\title{
Cognitive deficits in children treated for leukaemia
}

\author{
Christine Eiser
}

\section{Psychological effects of chronic childhood diseases}

In common with children who have other chronic diseases, those with leukaemia experience a great many restrictions and disadvantages; school life is inevitably interrupted, and many children miss several months schooling immediately after diagnosis. ${ }^{12}$ All children are regularly absent during the course of their treatment either for routine hospital appointments, because of minor infections, or because of outbreaks of contagious diseases-such as measles or chickenpox-among the other children.

Such interruptions can have adverse consequences both for their academic achievements and for social relationships. Continued absences mean that the children miss essential lessons, and are continuously behind in written work. Circles of friends may regroup and exclude ill children, who may also return to school changed people, both in appearance and in character. A feeling of isolation can reduce the children's sense of belonging to the school and their participation in activities.

Other factors, too, work against chronically sick children in the classroom. Teachers are poorly informed about the implications of disease and may feel reticent about having to teach such children. Many fail to understand the nature of medical complications, and worry that they will be unable to deal with medical emergencies should they arise. A great deal has also been written about the extent to which teachers have reduced expectations about how far chronically sick children should participate in all school activities, or perform academically. These dilemmas have been noted particularly among teachers of children with asthma ${ }^{3}$ and diabetes, ${ }^{4}$ as well as among teachers generally. ${ }^{5}$ Teachers also tend to rate children with cancers as less sociable and more isolated and withdrawn than their healthy peers. ${ }^{6}$

Parents, too, may communicate to sick children that school attendance and academic achievement are less important after the diagnosis of a chronic condition. Many parents report that such diagnoses force them to put their various ideas into perspective, and acknowledge the importance of less materialistic and competitive ideals. $^{7}$

Children with chronic diseases typically experience some restrictions of activities, especially in terms of mobility or participation in sports activities. This applies no less to those with leukaemia.
Given these restrictions and disadvantages, it should not be surprising that children with chronic diseases commonly show deficits in intellectual achievements, ${ }^{8} 910$ and in behavioural and social functioning. ${ }^{11}$ Certain 'risk' factors-especially social disadvantage or the occurrence of other medical complications, as well as the characteristics of the disease itself (such as the extent to which it is associated with visible deficits or reduces the child's mobility)seem to aggravate the possibility of adverse psychological repercussions. ${ }^{1213}$

For those with leukaemia there is the additional 'risk factor' of their treatment regimens. Both radiotherapy and chemotherapy have been implicated as potential sources of damage to the developing central nervous system. Sometime after the introduction of this treatment protocol parents began to report difficulties for their children at school. ${ }^{14}$ Typically, poor performance was noted especially in mathematics, problem solving, attention, and concentration skills.

Moss and Nannis argued that central nervous system prophylaxis may be particularly damaging for young children, as compensatory mechanisms are less likely to operate when radiation treatment includes the whole brain. ${ }^{15}$ They hypothesised that greater intellectual impairment would also occur in younger children who received radiation treatment before the brain was fully developed (below 5 years). Deficits could be expected to become more noticeable with time. This hypothesis is based on the assumption that new learning is more affected than previously acquired skills, and that generalised damage early in life has a profound effect on the individual child.

Given parental reports of underachievement, and the possibility of radiation induced damage to the central nervous system, a considerable amount of research has been generated concerned with the short term and long term effects of treatment for leukaemia on the intelligence quotients (IQ) and academic achievements of children with the disease.

I will now consider how adequately this research has been designed and carried out, what conclusions can be drawn, and what implications may be drawn for the education of these children.

Problems in study design

To put the research findings into perspective, I 
will first consider the problems in study design that are encountered in work of this kind.

First of all, it is impossible to show conclusively that any deficits in intelligence or behaviour that are observed are directly attributable to radiotherapy, chemotherapy, or any other disadvantages of the disease experienced by the child and family. For ethical reasons it is impossible to conduct the controlled experiments that would be necessary to reach such conclusions. With few exceptions, researchers have failed to acknowledge the interdependence of these factors.

Secondly, there has been an over-reliance on IQ scores as the outcome measure. IQ scores are themselves subject to considerable variability (as a function of the child's motivation or the testing style of the examiner). They are unlikely to be sufficiently sensitive to monitor fluctuations or gradual declines in ability, and they are not valid indicators of the child's ability outside the traditional classroom setting.

Thirdly, there has always been the vexed question of the suitability of different 'control' groups. The result has been that children's scores may be compared with standardised norms, scores of 'healthy' children (matched for age, gender, and social class), healthy siblings, or children with other chronic or acute conditions. Though all of these comparisons have some merits, none are likely to yield a definitive answer.

Fourthly, researchers have for convenience opted for 'cross sectional' designs. More rarely, longitudinal studies have been conducted. Though the longitudinal method is essential to understand the processes by which deficits may occur, many difficulties arise concerning patient attrition and repeated testing. In addition, specific aspects of treatment may change depending on the child's progress. For all these reasons, longitudinal studies have not always yielded findings that are as clearcut as might have been hoped.

\section{Review of published reports}

A report by Soni et al showed no differences in IQ scores between children treated for leukaemia by irradiation of the central nervous system, either in comparison with a 'control' group of patients treated without irradiation, or with a group of patients with solid tumours. ${ }^{16}$ The number of children taking part was small, however, and there was a five year difference in the mean age of those with leukaemia treated by irradiation of the central nervous system and the control group with solid tumours. These findings were replicated in other studies. ${ }^{1720}$

A substantial number of reports, however, did suggest that children treated by irradiation of the central nervous system, or methotrexate, or both, did show IQ deficits compared with both healthy controls and with children with other cancers who were not treated in this way. The question became therefore not whether irradiation of the central nervous system was associated with deficits at all, but rather which children or skills were most vulnerable.

\section{Gender}

One of the most consistent findings to emerge was that cognitive impairment after irradiation was more common and more severe in girls than in boys. ${ }^{21} 22$ Waber et al, for example, found that $89 \%$ of girls and $54 \%$ of boys showed some learning impairment measured by a conglomerate index of IQ and academic achievement. ${ }^{22}$ Though this was consistent with the related finding of more impairment of growth in girls, ${ }^{22}$ the results were not borne out by other work that indicated that there was greater vulnerability among boys. ${ }^{24}$ Waber et al proposed a two stage model to account for these findings. ${ }^{25}$ One set of processes were hypothesised to affect all children treated by irradiation of the central nervous system and tended to increase the incidence of cognitive dysfunction and learning disorders. The second was developmentally determined and affected only girls, with the result that boys showed impairment in discrete skills, and girls showed more generalised impairment.

\section{Age at diagnosis}

Perhaps one of the most important inferences was that children who were younger (especially under 3 years old) were more vulnerable than children who began treatment later. ${ }^{21}$ 26-30 These studies were often based on samples of children still undergoing treatment or who had only recently completed treatment, and seemed to support the hypothesis put forward by Moss and Nannis that younger children would be more vulnerable. ${ }^{15}$ This might also be predicted from understanding changes in the social or emotional impact of the disease depending on the child's age. ${ }^{31}$ Other work concerned with long term survivors has, however, not confirmed the hypothesis of continual declines in performance after treatment. ${ }^{32}$

\section{Specific compared with generalised deficits}

Although a number of studies suggested that irradiation of the central nervous system resulted in a mild generalised loss in ability, ${ }^{33}$ a number of other studies pointed to discrete losses in specific skills. For example, it was noted that particular deficits occurred in quantitative, memory, and motor skills, especially for those treated by irradiation before they were 5 years old. ${ }^{26}$

The possibility that there were specific cognitive deficits has been noted by others. ${ }^{921}$ Deficits were noted particularly in mathematical skills, attention, concentration, and memory. It is not clear why this should be so. It may be that mathematical skills are easier to measure than linguistic or creative skills, or that differences in the way that children are taught makes it more difficult for the child to make up for absences in mathematics. It is possible that the deficits in mathematical skills have been overemphasised. In this respect, it should be noted that Peckham et al reported that the range of deficits shown in their sample was wide and therefore the repercussions of radiation were 
determined in part by individual and genetic factors, in addition to the treatments. ${ }^{34}$

\section{Integration of results}

Cousens et al attempted to put some order into this area by conducting a meta-analysis of all research published between 1975 and $1985 .^{35}$

Of these 30 studies, 17 were included in the meta-analysis, as only these fulfilled the criteria of having patients with acute lymphatic leukaemia who were treated with cranial irradiation as subjects and a control group in which irradiation was not used, and of providing enough statistical information for a full scale 'IQ effect size' to be calculated. The effect size was calculated from the difference between the mean scores of the control and treatment groups divided by the standard deviation of the control group scores. In addition, 10 variables were coded wherever possible, including the number of patients and controls, mean age at testing for patients and controls, age at diagnosis or irradiation for patients, number of units of radiation given, duration of treatment, time since treatment, type of control group, and IQ measuring instrument used.

The mean overall effect size was -0.72 , equivalent to an IQ deficit of about 11 points. Three variables correlated significantly with the effect size $(p<0.05)$ : (i) the age of the patients at the time of diagnosis (showing greater decrements the younger the patients were diagnosed); (ii) the age at testing of the controls (again showing greater decrements the younger they were at the time of testing); and (iii) the control group (greater decrements being found when healthy controls were compared with control groups who had other types of cancer).

The association between effect size and length of time since end of treatment was not significant, though greater decrements were associated with longer lapses of time since the completion of treatment. There were no associations between effect size and size of the sample or control groups, age at testing of patients, length of treatment, instrument used to measure IQ, or specific control group.

Subsequent analyses were conducted on two separate groups of studies, those in which patients were under 5 years of age at the time of irradiation, and an older group. The younger group $(n=12)$ had a mean effect size of -0.82 compared with the older group $(n=11)$ with a mean effect size of -0.53 .

From this analysis, Cousens et al concluded that patients receiving prophylactic treatment including irradiation of the central nervous system showed a decrease in full scale IQ score (in the order of 11 points). ${ }^{35}$ In addition, children treated at younger ages showed greater deficits. They calculated a mean loss of 17 points for children treated before 4 years of age, compared with 7 points for those treated later. They also suggest that IQ scores do not drop to their lowest levels until some time after treatment. Greater decrements were observed in studies in which children had been treated at least three years earlier $(n=18)$ compared with those treated more recently $(n=5)$.
Although the meta-analysis was excellent in the way in which it drew together much of the published work and indicated the mean decrement in IQ, it is an inappropriate technique for studying other issues. For example, it is still not clear whether patients have a generalised deficit in IQ, or whether specific skills are affected, nor is it clear whether IQ decrements are continuous and progressive, nor if there is a point at which scores stabilise, and even some recovery occurs. We know relatively little about the effects of irradiation as a function of gender, or social class, yet both these may be critical mediators of decrements.

\section{Long term survivors}

Most of the work reviewed so far has been based on patients who were treated for leukaemia and survived without recurrence over relatively short periods of time (up to five years). As the numbers of patients who survive even longer has increased, interest has slowly shifted towards the consequences for those patients. Research concerned with long term survivors is of interest for two reasons. Firstly, it is necessary to establish whether children who are well, and have completed treatment, show the same kind of deficits as those who are in shorter term remission. This is relevant to the practical question of whether these children continue to need remedial help at a time when they are considered to be medically 'cured'. Secondly, the study of long term survivors is relevant to the issue of how irradiation of the central nervous system affects development; the issue is whether children's abilities are permanently blunted, or if and when intellectual recovery occurs.

Malpas suggested that achievements at school leaving age (in terms of examination passes) compared favourably with those of the rest of the population. ${ }^{36}$ Subtle deficits in long term survivors have, however, been identified by Mulhern et al and Peckham et al. ${ }^{32} 34$

Peckham et al studied 23 children who had been treated by irradiation of the central nervous system and intrathecal methotrexate 810 years earlier. ${ }^{34}$ Lower than expected scores were obtained in both reading and mathematics after consideration of scores before treatment and currently. Difficulties were noted particularly in attention and concentration, memory, sequencing, and comprehension. They argued that long term survivors showed specific deficits rather than generalised retardation. Despite this some children seemed to achieve appreciably more than expected, presumably reflecting the fact that individual or remedial help and parental support could do much to alleviate the potential damage of treatment of the leukaemia.

In a comparable study, Mulhern et al studied 183 children all of whom had been treated for cancer at least five years earlier and were currently free of disease. ${ }^{32}$ Problems with both academic work and adjustment were found among children who were older on beginning treatment, who had been treated by irradiation of the central nervous system, and who lived in one parent families. Both these studies pointed 
to the continuing need to support and offer remedial help to long term survivors. Inevitably, however, children in this kind of study were treated some time ago, and therefore may have received different-perhaps less acceptable-treatment compared with today's standards.

\section{Interventions and implications}

Most studies concluded that children with leukaemia treated by irradiation of the central nervous system should be offered additional educational help at school. Mulhern et al, for example, suggested that deficits could be identified in long term survivors indicating that remedial help may be advisable throughout treatment and for many years after. ${ }^{32}$

We have, however, made little progress in determining the kind of remedial help that may be most beneficial. Though additional individual help with basic skills may alleviate the worst side effects of irradiation, real progress in modifying specific deficits can be achieved only by the development of programmes aimed directly at the particular cognitive deficits that children experience. There are consistent indications that concentration and attention skills, or problem solving abilities, are most likely to be affected. Remedial help needs to be concentrated on developing these skills, rather than relying on methods to help healthy children with more general learning difficulties.

It is also naive to assume that academic achievement is determined solely (or even predominantly) by educational interventions. Children's achievements in school are also dependent on intrapersonal factors such as self esteem and coping skills, as well as position within the peer group. We know that children with leukaemia can experience lowered self esteem and can be subject to teasing from peers. ${ }^{35}$ In a study of 138 long term survivors who had completed treatment, Greenberg et al found that, although most children scored within normal limits on measures on selfconcept, depression, and locus of control, a proportion showed significantly lower scores. ${ }^{37}$ Those with residual deficits had poorer self concept, more depressive symptoms, and a more external locus of control compared with those with mild deficits or none at all. In the final analysis, however, perhaps we need to examine the fundamental question we are asking. Research has focused on identifying 'cognitive deficits' in children treated by irradiation of the central nervous system, and while acknowledging the difficulties inherent in such an approach, most workers have nevertheless made the assumption that somehow radiation effects would outweigh any disadvantages to the social or emotional experiences of the family. There are, however, many reports that suggest that the children themselves may suffer adverse emotional consequences and depression, ${ }^{38}$ and that families undergo enormous upheaval and stress. ${ }^{39} 40$ Even healthy siblings can be adversely affected. ${ }^{41}$ The treatment that is currently offered to children with leukaemia may ultimately be shown to be associated with some iatrogenic effects, but for the moment these are not proved. It is possible and highly desirable, however, that in the meantime interventions are directed at those consequences of treatment that are more easily identifiable. Routine liaisons with schools and teaching personnel should be offered, and psychological support (in addition to practical or financial help) provided for all family members who need it.

For children themselves interventions may need to foster intrapersonal and interpersonal skills in addition to focusing on academic abilities. Children with leukaemia may need to explain their disease, its treatment, and implications to others, and can experience considerable unease in doing so. These difficulties are of course shared by children with other chronic diseases. For example, those with diabetes may need to explain why they need injections, or why they may need to eat before physical activities. There is evidence that children with diabetes $^{42-44}$ and asthma ${ }^{45}$ can benefit from training in 'social skills', which may help them resolve and deal with difficult social encounters. It may well be that these approaches need to be integrated with more straightforward educational interventions if we are really going to help children with leukaemia to be thoroughly integrated and competitive with their peers.

I thank Dr Andrew McNinch of the Royal Devon and Exeter Hospital, Wonford, for his comments. The author is funded by a research grant from the Economic and Social Science Research Council.

1 Eiser C. How leukaemia affects a child's schooling. British Fournal of Social and Clinical Psychology 1980;19:365-8. 2 Lansky SB, Cairns NV, Zwartjes W. School attendance among children with cancer: a report from two centers. Fournal of Psychosocial Oncology 1983;1:75-82.

3 Hill RA, Standen PJ, Tattersfield AE. Asthma, wheezing, and school absence in primary schools. Arch Dis Child and school absence

4 Bradbury AJ, Smith CS. An assessment of the diabetic knowledge of school teachers. Arch Dis Child 1983;58: knowledg.

5 Eiser C, Town C. Teachers' concerns about chronically sick children. Implications for paediatricians. Dev Med Child Neurol 1987;29:56-63.

6 Noll RB, Bukowski WM, Rogosch FA, LeRoy S, Kulkarni $\mathbf{R}$. Social interactions between children with cancer and their peers: teacher ratings. $\mathcal{F}$ Pediatr Psychol 1990;15:43-56.

7 Spinetta JJ, Murphy JL, Vik PJ, Day J, Mott MA. Long term adjustment in families of children with cancer. $\mathcal{F}$ oumal of Psychosocial Oncology 1989;6:179-91.

8 Ryan C, Vega A, Drash A. Cognitive deficits in adolescents who developed diabetes early in life. Pediatrics 1985;75: 921-7.

9 Mearig JS. Cognitive development of chronically ill children. In: Hobbs N, Perrin JM, eds. Issues in the care of children with chronic illness. San Francisco: Jossey Bass, 1985: with chronic

10 Eiser C. Effects of chronic illness on the child's intellectual development. $7 R$ Soc Med 1986;79:2-3.

11 Ungerer J, Horgan B, Chaitow J, Champion GB. Psychosocial functioning in children and young adults with social functioning in children and young ad
juvenile arthritis. $f$ Pediatr 1988;81:195-202.

12 Cadman D, Boyle M, Szatmari P, Offord DR. Chronic illness, disability, and mental and social well-being: findings of the Ontario Child Health Study. Pediatrics 1987;79:80512.

13 Eiser C. Chronic childhood disease: an introduction to psychological theory and research. Cambridge: Cambridge University Press, 1990

14 Meadows AT, Massari DJ, Fergusson J, Gordon J, Littman P, Moss K. Declines in IQ scores and cognitive dysfunctions in children with acute lymphocytic leukemia with cranial irradiation. Lancet 1981 ;ii:1015-8.

15 Moss HA, Nannis ED. Psychological effects of central nervous system treatment of children with acute lymphocytic leukemia. In: Kellerman J, ed. Psychological aspects of childhood cancer. Springfield: Thomas 1980:171-83.

16 Soni SS, Marten GW, Pitner SE, Duenas DA, Powazek M. Effects of central-nervous-system irradiation on neuroEffects of central-nervous-system irradiation on neuro-
psychologic functioning of children with acute lymphocytic leukemia. N Engl f Med 1975;293:113-8. 
17 Verzosa MS, Aur RJA, Simone JV, Hustu HO, Pinkel DP Five years after central nervous system irradiation of children with leukaemia. International fournal of Radiation and Oncology 1976;1:209-15.

18 Berg RA, Ch'ien LT, Bowman WP, et al. The neuropsychological effects of acute lymphocytic leukemia and its treatment-a three-year report: intellectual functioning and academic achievement. Clinical Neuropsychology 1983;5: 9-13.

19 Ivnik RJ, Colligan RC, Obetz SW, Smithson WA. Neuropsychologic performance among children in remission from acute lymphocytic leukemia. Developmental and Behavioral Pediatrics 1981;2:29-34.

20 Whitt JK, Wells RJ, Lauria MM, Wilhelm Cl, McMillan CW. Cranial radiation in childhood acute lymphocytic leukaemia: neuropsychological sequelae. Am $\mathrm{f}$ Dis Child 1984;138:730-6.

21 Jannoun $L$. Are cognitive and educational development affected by age at which prophylactic therapy is given in affected by age at which prophylactic therapy is given in acute 1 . 953 .

22 Waber DP, Urion DK, Tarbell NJ, Niemeyer C, Gelber R, Sallan S. Late-effects of central nervous system treatmen in long-term survivors of childhood acute leukaemia are

23 Zurlo MG, Senesi E, Terranni B, et al. Height of children of therapy after acute lymphoblastic leukaemia. Pediatric Hematology and Oncology 1988;5:187-95.

24 Taylor DC. Mechanisms of sex differentiation-evidence from disease. In: Ghesquiere J, Martin RD, Newcombe F eds. Human sexual dimophism. London: Taylor and Francis, 1985:169-90.

25 Waber DP, Gioia G, Paccia J, et al. Sex differences in congnitive processing in children treated with CNS prophylaxis for acute lymphoblastic leukaemia. $\mathcal{F}$ Pediatr Psychol $1990 ; 15: 105-22$

26 Eiser C, Lansdown R. Retrospective study of intellectual development in children treated for acute lymphoblastic development in children treated for acute

27 Moss HA, Nannis ED, Poplack DG. The effects of prophylactic treatment of the central nervous system on the intellectual functioning of children with acute lymphoblastic leukaemia. Am f Med 1981;71:47-52.

28 Stehbens JA, Kisker CT, Wilson BK. Achievement and intelligence test-retest performance in pediatric cance patients at diagnosis and one year later. $\mathcal{F}$ Pediatr Psychol 1983;8:47-56.

29 Said JA, Waters BGH, Cousens P, Stevens MM. Neuropsychological sequelae of central nervous system prophyaxis in survivors of childhood acute lymphoblastic leukemia. 7 Consult Clin Psychol 1989;57:251-6.

30 Robinson LL, Nesbit ME Jr, Sather HN, Meadows AT,
Ortega JA, Hammond GD. Factors associated with IQ scores in long-term survivors of childhood acute lymphoblastic leukaemia. Am $\mathcal{f}$ Pediatr Hematol Oncol 1984;6:11521.

31 Perrin EC, Gerrity PS. Development of children with a chronic illness. Pediatr Clin North Am 1984;31:19-31.

32 Mulhern RK, Wasserman AL, Friedman AG, Fairclough D. Social competence and behavioral adjustment of children who are long-term survivors of cancer. Pediatrics 1989;83: 18-25.

33 Rowland JH, Glidewell OJ, Sibley RF, et al for the Cancer and Leukemia Group B. Effects of different forms of central nervous system prophylaxis on neuropsychologic function in childhood leukemia. $\mathcal{F}$ Clin Oncol 1984;2:132735 .

34 Peckham VC, Meadows AT, Bartel N, Marrero O. Educational late effects in long-term survivors of childhood acute tymphocytic leukemia. Pediatrics 1988;81:127-33.

35 Cousens $P$, Waters B, Said J, Stevens $M$. Cognitive effects of cranial irradiation in leukaemia: a survey and metacranial irradiation in leukaemia: a survey and meta-

36 analysis. $\mathcal{F}$ Child Pychol Psychiatry 1988;29:839 Clinical Radiology 1988;39:166-72.

37 Greenberg HS, Kazak AE, Meadows AT. Psychologic functioning in 8- to 16-year-old cancer survivors and their parents. F Pediatr 1989;114:488-93.

38 Worchel FF, Nolan BF, Willson VL, Purser JS, Copeland DR, Pfefferbaum B. Assessment of depression in children with cancer. F Ped Psychol 1988;13:101-12.

39 Kazak AE, Meadows AT. Families of young adolescents who have survived cancer: social-emotional adjustment, adaptability and social support. $\mathcal{F}$ Pediatr Psychol 1989;14: 175-92.

40 Kupst M, Schulman J. Long-term coping with pediatric leukaemia: a six year follow-up study. $\mathcal{F}$ Pediatr Psycho 1988;13:7-22.

41 Lobato D, Faust D, Spirito A Examining the effects of chronic disease and disability on children's sibling relationchronic disease and disability on children's

42 Follansbee DJ, La Greca AM, Citrin WS. Coping skills training for adolescents with diabetes. Diabetes 1983;32(suppl ing for 147 .

43 Kaplan RM, Chadwick MW, Schimmel LE. Social learning intervention to promote metabolic control in type 1 diabetes mellitus: pilot experiment results. Diabetes Care 1985;8:152-5.

44 Gross AM, Johnson WG, Wildman HE, Mullett M. Coping skills training with insulin-dependent preadolescen diabetics. Child Behavior Therapy 1981;3:141-53.

45 Perrin JM, MacLean EW. Children with chronic illness: the prevention of dysfunction. Pediatr Clin N Am 1988;35: 1325-37. 